\title{
From Insects to Bioinspired Catalysis
}

\author{
Wolf-D. Woggon*
}

\begin{abstract}
The author describes the events leading to his PhD studies at the University of Zurich under the supervision of Prof. Hans Schmid and the evolution of his research interests into the field of biological chemistry resulting in the completion of his habilitation at UZH and ultimately a professorship at the University of Basel.
\end{abstract}

Keywords: Institute of Organic Chemistry UZH

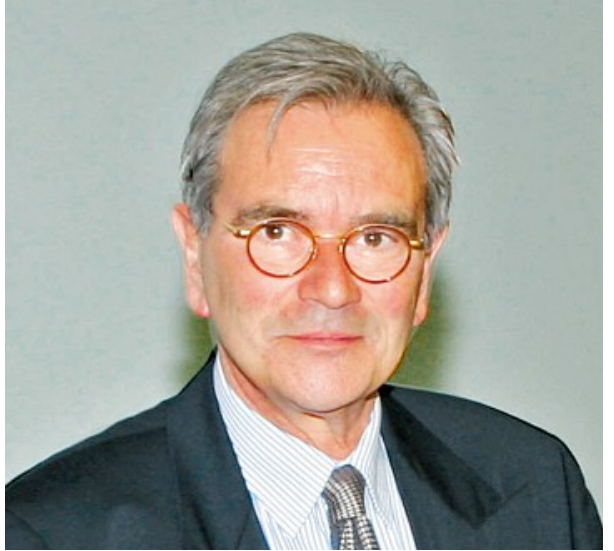

Wolf-D. Woggon
My attraction to Zurich came from an advertisement in Angewandte Chemie that described a $\mathrm{PhD}$ project on insect pheromones. The topic provided a substantial draw for somebody like me who had followed a studium generale - BSc in Geology, MSc in Chemistry - at the Freie Universität Berlin. My first encounter with Hans Schmid in April 1969 was somewhat symptomatic for our relationship. Hans Schmid said: "I don't know anybody in Organic Chemistry at the FU-Berlin"; and I was so embarrassed that I replied: "nobody there knows you either" - he laughed and appointed me to start my $\mathrm{PhD}$ at the end of 1969

Schmid afforded me the privilege to work in the 'Privat-Labor', a lab adjacent to Schmid's office, which inherited its name from the time of Karrer. It was a rather small lab with four benches occupied by Armin Guggisberg, the 'left-hand' of Schmid, Anthony Gorman, Vincent Agwada, all working on alkaloids, and Martin G. Peter who

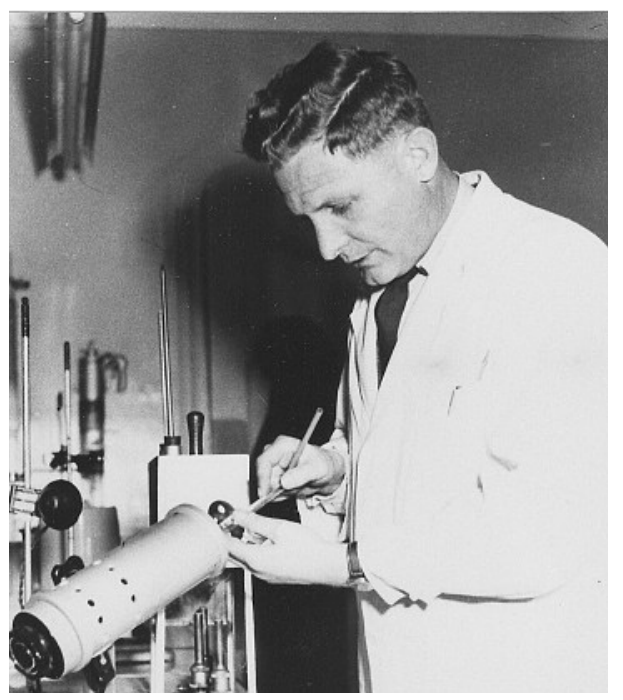

Hans Schmid had started his PhD a year earlier. Martin and Armin were gifted experimentalists and I profited a lot from their experience.

Martin and I worked together, but approached our project from different angles, to solve the difficult biosynthesis of cantharidin 1, a toxic, crystalline substance,

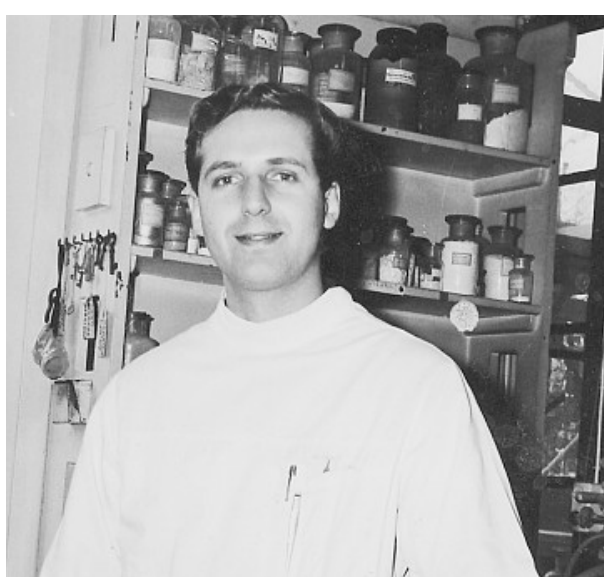

Armin Guggisberg

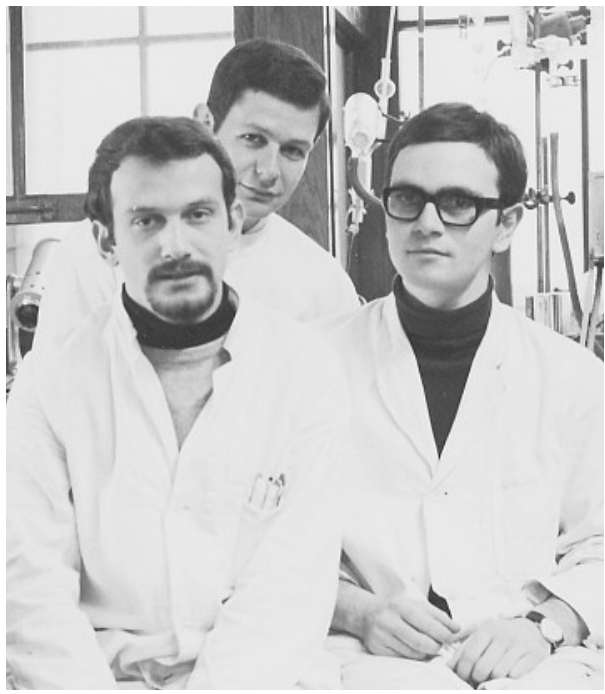

Martin G. Peter, Erich Waldner, WDW
Correspondence: Prof. Dr. W.-D. Woggon Department of Chemistry

iversity of Basel

$\mathrm{CH}-4056$ Basel

E-mail: wolf-d.woggon@unibas.ch 
isolated from blister beetles (Lytta vesicatoria). The isolate was also known to the Mediterranean people for its aphrodisiac features and hence even became a subject in literature (My Uncle Oswald, by Roald Dahl). At the time, this being a very up to date problem, juvenile hormone and many other insect hormones and pheromones had just been isolated and the general question was raised: are these molecules biosynthesized de novo? Our work proved that for cantharidin de novo biosynthesis was indeed the case.

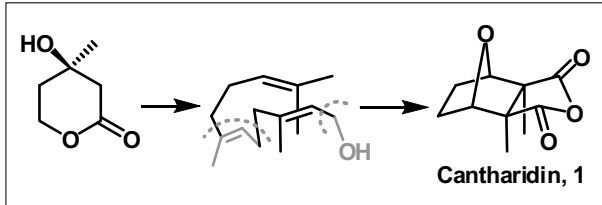

Fig. 1. Biosynthesis of cantharidin 1

About three years later Martin and I felt ready for $\mathrm{PhD}$ examination. Shortly thereafter Martin moved to the US and I stayed at UZH because Schmid offered me a permanent position to pursue my habilitation. Soon I had four PhD students to work with me and the future looked bright until Schmid died unexpectedly in Dec. 76 and everything collapsed. With him I lost my second father. He was without doubt a tough and demanding person but I admired him for his reliability, profound knowledge, extreme working capacity and very broad interest in various areas of organic chemistry.

After his death Schmid's colleagues took over and I had certain difficulties to convince them of the promises Schmid had made to me. Subsequently I was asked to give up the idea of an independent research group and to leave for a postdoc. Supported by an SNF grant I joined the group of Alan Battersby (Cambridge, UK). Working with Alan I learned the gentle way of leading a research group; he was a superb teacher and speaker and I enjoyed the stay profoundly, last but not least because it was scientifically successful. Alan convinced me to work on the synthesis of isobacteriochlorin model compounds such as $\mathbf{2}$ (Fig. 2), a joint project he had started with Albert Eschenmoser. I was able to solve some synthetic problems en route and to prepare and characterize these macrocycles as analogues of $\mathrm{B}_{12}$-precursors. Beside and together with Reinhard Neier, I had the good fortune to contribute to the structure determination of the C-20 methylated precorrin 3 from $P$. shermanii, which ring-contracts to the corrin macrocycle.

Back in Zurich-Irchel, I continued my habilitation on my own trying to solve various problems of the biosynthesis of arthropod pheromones and by that gradually moved towards metal-organic chemistry.

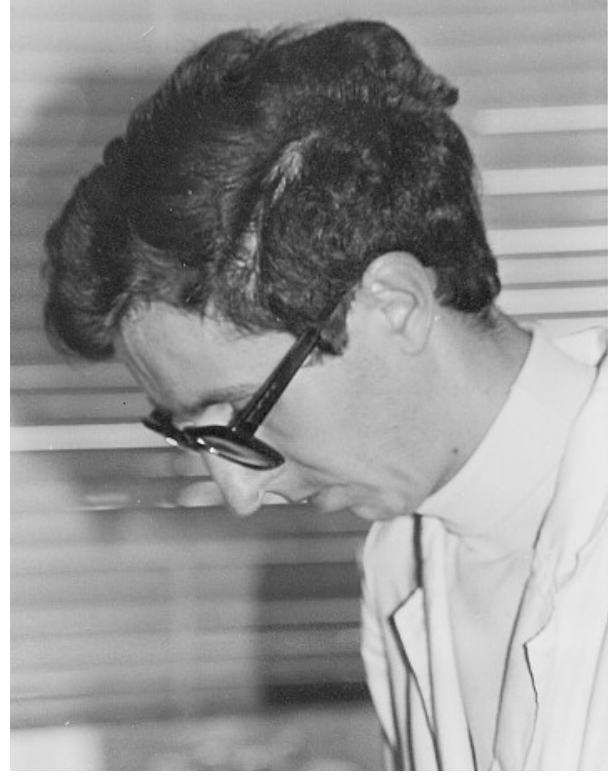

Reinhard Neier

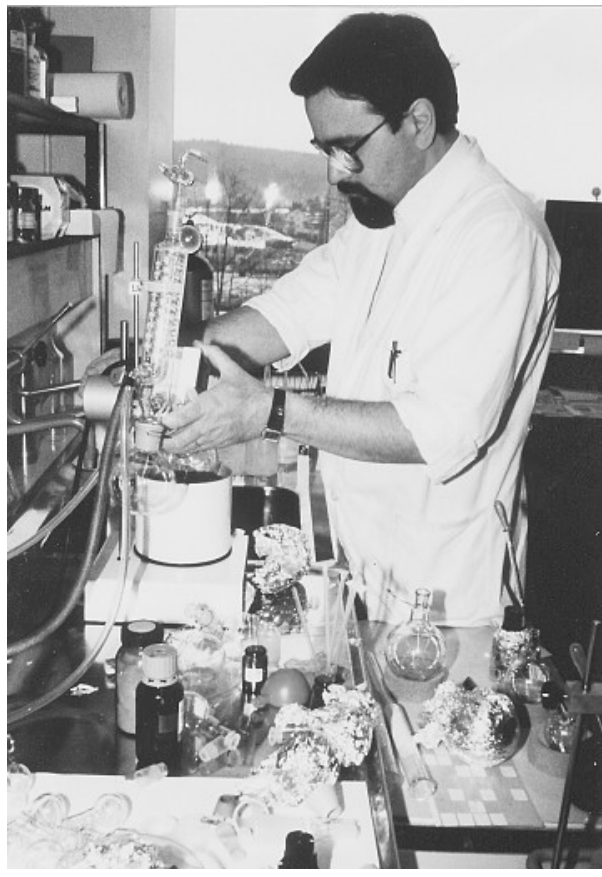

WDW still at the bench
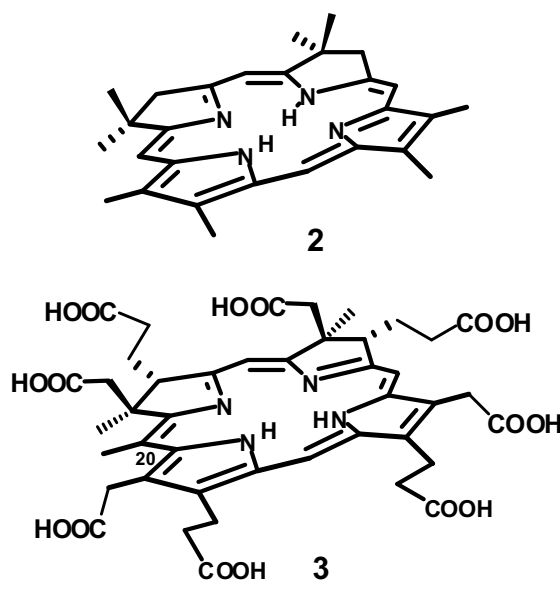

Fig. 2. Vitamin $B_{12}$ precursors
Finally, I was granted the title 'Privatdozent' shortly after my colleagues Martin Karpf and Peter Rüedi got their degrees. The title 'PD' opened the door to new endeavors and to research money from the Hans-Schmid Foundation and the SNF.

Against tough competition from celebrities such as Jack Baldwin, Jim Collman, and John Groves, I decided for a project on the synthesis of functional enzyme models of cytochrome P450. I was very lucky with the first two PhD students, Beat Stäubli and Heinz Fretz, who were very serious and experimentally skilled chemists; they prepared our first heme-thiolate complex 4 (Fig. 3). Later in a decisive experiment, Heiko Patzelt could demonstrate for the first time that the oxo-iron version of this $\mathrm{Fe}$ complex was indeed P450-like and capable of oxidizing non-activated $\mathrm{C}-\mathrm{H}$ bonds, i.e. one of the $\mathrm{CH}_{2}$ groups of the alkane-bridge spanning the porpyhrin. The 'porphyrin guys' were reinforced by Sandro Ghirlanda,

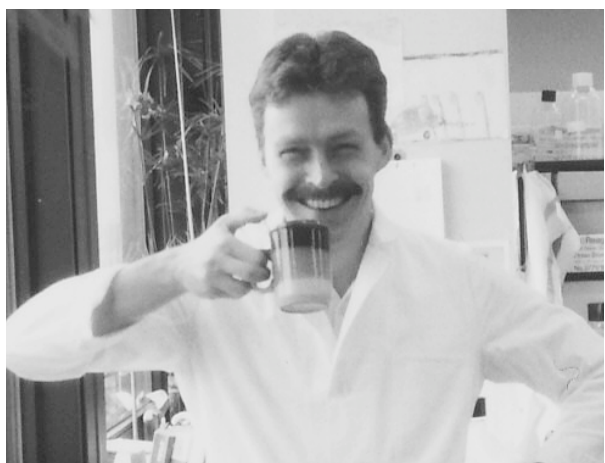

Beat Stäubli

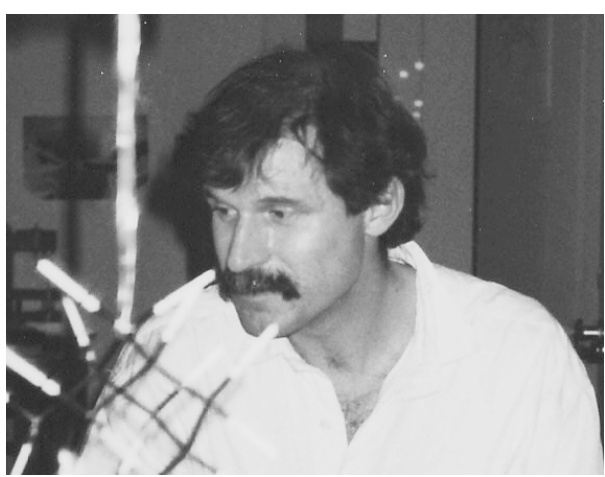

Heinz Fretz

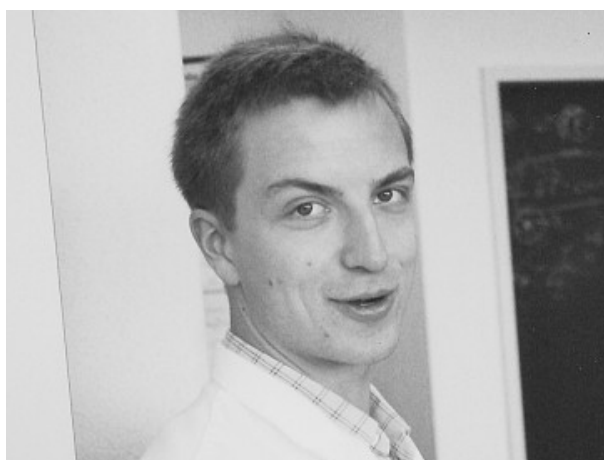

Heiko Patzelt 


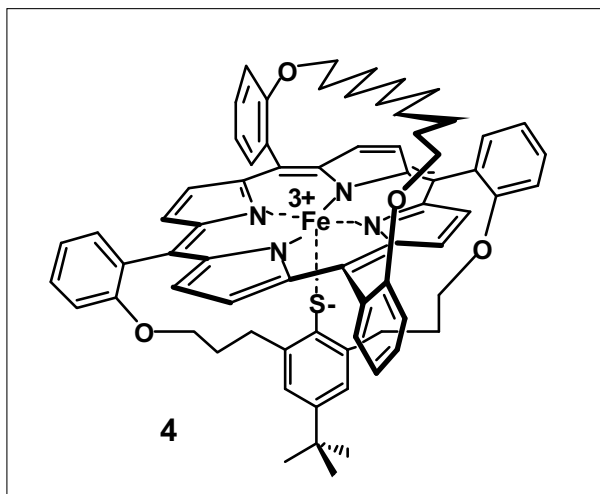

Fig. 3. Our first P450-enzyme model

a very fine synthetic chemist, and Christoph Gmür who was more interested in 'TVchemistry'. Both worked on the synthesis of P450 enzyme models with substrate recognition sites.

Simultaneously our research topics expanded towards more biological aspects. Using a P450 enzyme from Catharanthus roseus $\mathrm{H}$. Fretz demonstrated by means of ${ }^{3} \mathrm{H}-\mathrm{NMR}$ that a chiral, allylic methyl group is hydroxylated under retention of configuration

Through my connection to Hans-Jürgen Hansen I came to know the Vitamin Division of F. Hoffmann-La Roche and a longstanding cooperation began which was even continued when this division was sold to DSM. The initial project, aimed at identifying and isolating the enzyme that catalyzes chromanol ring closure to $\gamma$-tocopherol $\mathbf{5}$, was pursued by Achim Stocker and later supported by the microbiologist Haroun Frick.

Achim succeeded isolating the 'tocopherol cyclase' and he determined many of the characteristic features of this hydrophobic protein. Another vitamin project began in Zurich; Gabi Wirtz started the identification of the until then unexplored enzyme which cleaves $\beta$-carotene 6 to retinal 7 (Fig. 4);

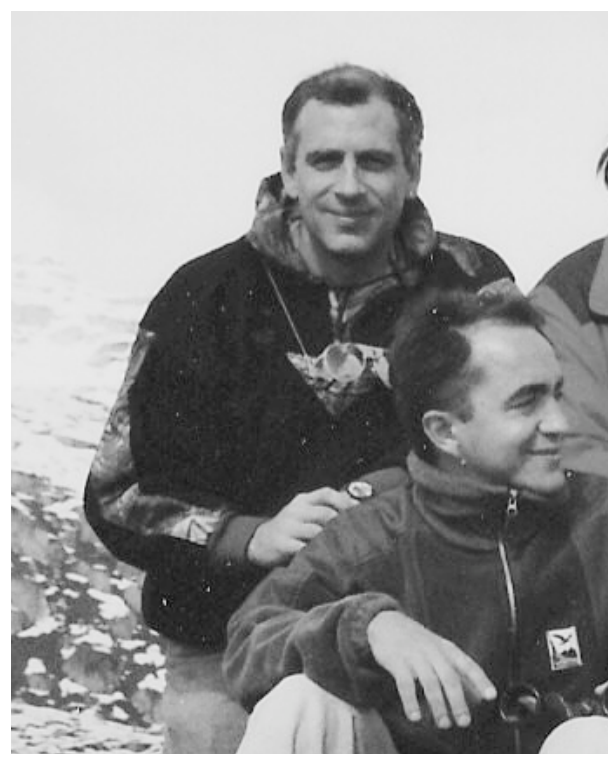

Haroun Frick, Achim Stocker

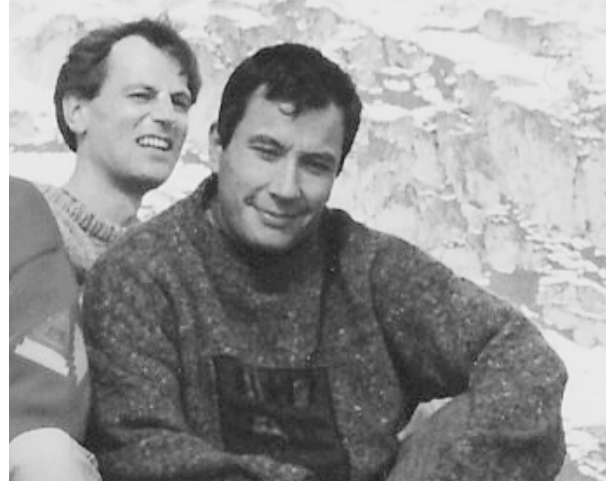

Christoph Gmür, Sandro Ghirlanda

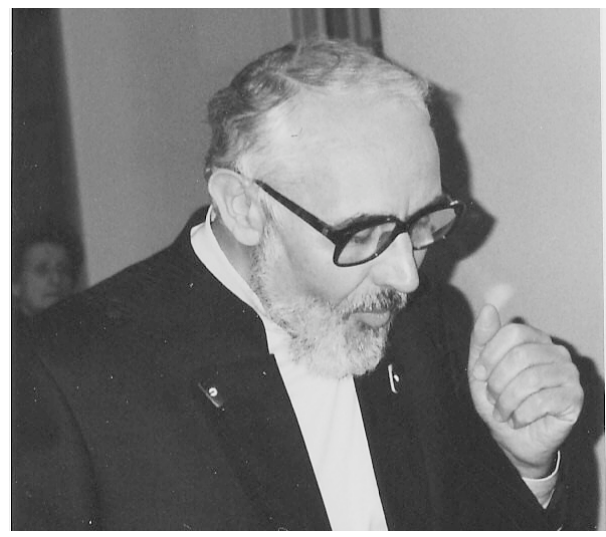

Hans-Jürgen Hansen

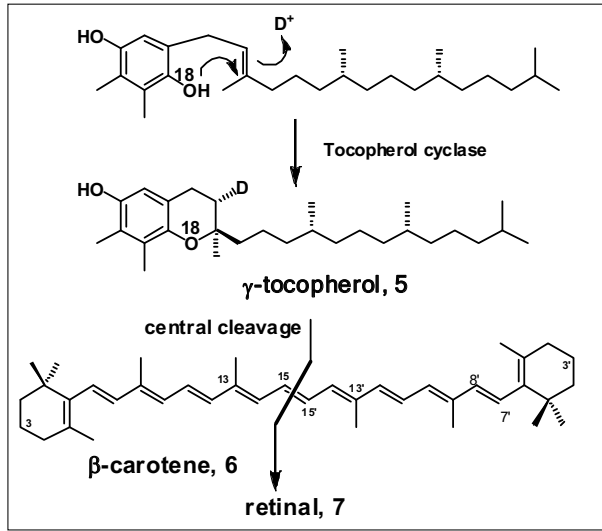

Fig. 4. Two enzymes discovered in the group

she completed the work successfully in Basel.

Last but not least, we started a very ambitious project to generate catalytic monoclonal antibodies with $\mathrm{P} 450$ reactivity. The hapten was carefully designed and synthesized by Stefan Matile and the theme was later continued by Adrian Ueberwasser. This small but rather efficient research group produced results that led to my appointment at the Chemistry Department of the University of Basel.

During the last twelve years in Basel I have enjoyed the really outstanding collegial atmosphere in the Department. I received full support for all of my research activities and also for my administrative duties as president of the 3eme cycle and head of the Department for several terms. I have

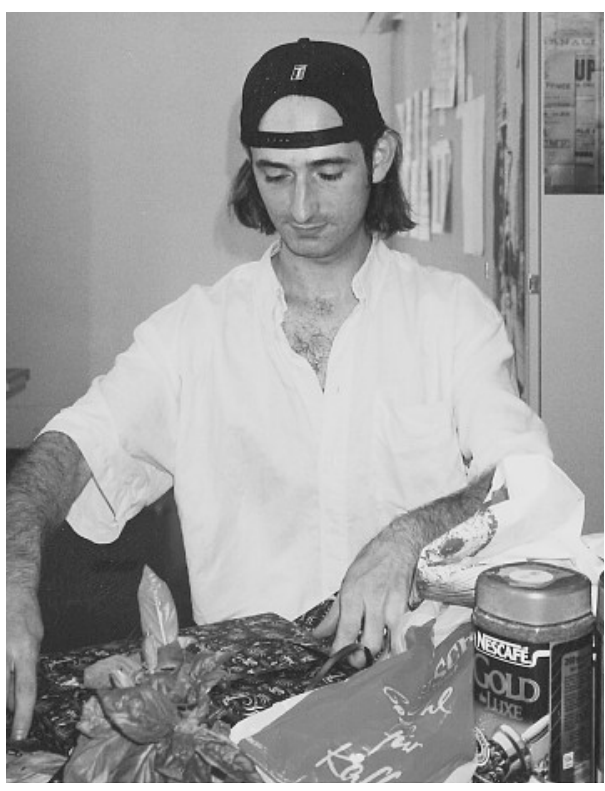

Stefan Matile

been able to maintain an excellent group of 12-16 PhDs and post-doctoral coworkers. Through the efforts of these talented people, we could contribute significantly to the advancement of bio-inspired catalysis.

At the edge of so-called retirement I am looking back at more than 30 years of teaching, i.e. educating hundreds of people of various disciplines. Concerning my own group, I am particularly happy that I could support some of my students to embark on a successful academic career: Martin Lochner, Roman Manetsch, Stefan Matile, Heiko Patzelt, Achim Stocker, H.-A. Wagenknecht and Xiao-an Zhang. After all, 'as time goes by', the positive aspects of my time in Zurich prevail; this period shaped my personal development, my research interests and turned out to be the nucleus for many subsequent research projects. Hence, I am very grateful to Manfred Hesse and Martha Kalt who unsuccessfully tried to teach me to avoid 'Fettnäpfchen', to the Institute for paying consumables, and to André Dreiding who welcomed me as an associate member of his group without any duty other than organizing group seminars in Zurich and Sils Maria. The company of the research group of André was a constant psychological support in particular during the years of my habilitation.

Also during my time in Zurich/Cambridge I made a number of long-lasting friendships namely with Georg and Marijke Fràter, Andrew Hamilton, Armin and Irma Guggisberg, Martin Karpf, Volkan Kisakürek, Reinhard Neier, Andreas and Madeleine Pfaltz and Jay Siegel. I am particularly grateful to Duilio Arigoni, Jack Baldwin, Alan Battersby and Albert Eschenmoser for constant support and encouragement during my time in Zurich and thereafter.

Received: January 21, 2008 